\section{PRACTICAL MODERN MICROSCOPY}

Traité de Microscopie

Instruments et Techniques. Par A. Policerd, M. Bessis et M. Locquin. Pp. vi +608 . (Paris : Masson et Cie., 1957.) Broché, 4,500 francs ; Cartonnétoile, 5,200 francs.

$r$ HIS book is concerned with the use of modern microscopes in biology. It contains much information that would be valuable to all users of microscopes, but it is especially well suited to the needs of pathologists, histologists and cytologists. The attempt to cover the requirements of these three groups in a single volume is becoming increasingly difficult, for new instruments and techniques are being invented one after another in almost bewildering profusion. The authors make a bold attempt to deal with the whole subject, from direct microscopy with the light microscope through phase-contrast and interference to electron-microscopy. The book is logically arranged and can be used as a work of reference as well as a text for systematic study. It can be strongly recommended. There is probably no other single volume that contains so much useful, up-to-date information on the subject. It is adapted throughout to the needs of the practical man, anxious to get the best results from his instruments by the use of rational techniques but not interested in the niceties of physical and chemical explanations.

In writing such a book as this, it is difficult to know how much physical and chemical explanation to include. Some of the theoretical sections are not satisfactory. A considerable amount of space is devoted to the theory of phase-contrast. It would not seem that the authors have had much experience in explaining the optical principles involved to intelligent persons ignorant of the subject. The treatment is neither well adapted to the needs of the beginner nor helpful to the initisted. It is possible to explain phase-contrast in a much more straightforward way, without any sacrifice of accuracy. The remarks on the theory of fixation and dyeing also leave a good deal to be desired. Indeed, it seems questionable whether the short sections on these subjects were worth including in the book. One might get the impression from the general remarks on pp. 289-290 that almost nothing is known about the chemistry of dyeing. In fact, of course, there is an immense wealth of knowledge, gained by the researches of Ehrlich, Fischer, Mann, von Möllendorff, Seki, Lison, Singer, and many others.

The balance of the book is on the whole good, though there may be a few subjects to which an unnecessary amount of space is devoted (secondary fluorescence, for example, and the shadowing of objects for light microscopy). Insufficient informstion is given on certain other subjects. It would not be possible to use collodion successfully as an embedding medium without more detailed instructions than are given here. Not nearly enough space is devoted to vital coloration. This important branch of microtechnique has unfortunately been pushed into the background by the invention of phase-contrast. Two objects that look identioal by phase-contrast may react very differently to vital dyes, and a pointer may thus be given to differences of chemical composition. The techniques of vital colouring are not very easy to learn, and the account given in this book is insdequate.
The book contains a few mistakes in matters of fact. For example, neutral red is said to be a neutral dye, and the cochinesl insect is described as a beetle; there is no mention of the use of tannin in the instructions for carrying out del Río-Hortega's tanninsilver method. There are some queer words in the list of English equivelents of French technical terms (falx image, gelatinous glycerin (for glycerine-jelly), kristall, microscop, prisma, etc.).

A defect of the book is the casual way in which the illustrations are introduced. Many of them are not referred to in the text, and one might suppose that they were chosen after the book had been written. The legends do not suffice in all cases to make the meaning clear.

The merits of this book greatly outweigh the minor defects that have been mentioned. It is clear, logical, modern, comprehensive, and eminently useful.

JOHN R. BAKER

\section{H. K. MOOKERJEE MEMORIAL VOLUME}

H. K. Mookerjee Memorial Volume of the Proceedings of the Zoological Society, Calcutta Edited by J. L. Bhaduri, B. Biswas and S. P. RayChaudhuri. Pp. ix $+396+21$ plates. (Calcutta: The Zoological Society, 1957.) Rs. 30; $50 s$.

DROF. MOOKERJEE had a distinguished career, both in Great Britain and in India, where he was the first occupant of the Sir Nil Ratan Sircar professorship of zoology at Calcutta. His influence on the development of Indian zoology is outstanding. When he was a student, teaching in zoology was intended for medical students and there was no special course of study in zoology followed in Bengal. The fact that thirteen contributions of the present issue have been written by Indian zoologists is ample evidence of his achievement in fostering the study of zoology in India.

In this memorial volume, thirty-two contributions are collected dealing with almost all aspects of zoology. They range from an article on "Sex Determination in Metazoa" by J. B. S. Haldane to an essay on "The Growth of Knowledge of Animals in Palestine from Prleolithic Times" by F. S. Bodenheimer. There are notes on mammals collected during a Himalayan Expedition by Biswamoy Biswas and $H$. Khajuria, and a study of the chromosome numbers in human cervical cencer by G. K. Manne.

Of the thirty-two papers, four deal with sex determination and genetics; four with cytogenetics; four with experimental biology ; four with descriptive embryology; ten with evolution and systematics; and the remaining ones with entomology and protozoology, except for a contribution on palæozoology. It is obviously impossible to review in a brief spece any of the contents of this book adequately, but it is perhape worth while pointing out that of the nonIndian contributions, eight come from the United States, seven from the United Kingdom, one from the U.S.S.R., two from Australia and one from Israel, thus again bearing testimony to Prof. Mookerjee's influence on the development of zoology, not only in his own country but also abrosd.

Indeed, the collection of papers on so many unrelated subjects, which at first sight appears somewhat haphazard, may be taken as a tribute to the width of Prof. Mookerjee's interests. A. GltcksmanN 